\title{
Recovery of bis(1-chloro-2-propyl) ether from aqueous solution onto acti- vated carbon
}

\author{
Robert Pełech \\ West Pomeranian University of Technology, Szczecin, Institute of Chemical Organic Technology, ul. Pulaskiego 10, \\ 70-322 Szczecin, Poland \\ Corresponding author: ul. Pułaskiego 10, 70-322 Szczecin, Poland, e-mail: Robert.Pelech@zut.edu.pl
}

\begin{abstract}
The results of the studies of bis(1-chloro-2-propyl) ether adsorption from aqueous solution onto AG5 activated carbon were presented here. Dynamic adsorptivity, mass transfer zone and the velocity of the adsorption front of the $10 \mathrm{~cm}$ adsorption bed depth for the velocity of flow 9 and $25 \mathrm{~cm} / \mathrm{min}$ were determined. For the regeneration of the adsorption bed, acetone rinsing was used. Total washout of adsorbed bis(1-chloro2-propyl) ether from the bed was obtained. After the regeneration the adsorbent has not shown deterioration of adsorption properties. To isolate bis(1-chloro-2-propyl) ether from acetone, distillation was used.
\end{abstract}

Keywords: activated carbon, adsorbent regeneration, adsorption, bis(1-chloro-2-propyl) ether, waste.

\section{INTRODUCTION}

Waste impurities are often the compounds of hard degradation with a lot of disadvantageous properties such as carcinogenity and mutagenity. Their durability causes that their emission, even in a small amount, cumulates and has a long-lasting negative influence on the environment. Among that type of compounds there are, for example, chlorinated propyl ethers (CIPE). A source of CIPE may be the installations producing propylene oxide and epichlorohydrin. Their increased content was found e.g. in the Elbe River and the North Sea waters. Those compounds were also found in the meat of the fish living there. On the basis of the research conducted along the Elbe River, it was stated that the CIPE content varies in the range of concentrations from 2 to $6 \mu \mathrm{g} / \mathrm{dm}^{3}$. At the river mouth the concentration equaled $650 \mathrm{ng} / \mathrm{dm}^{3}$ and the similar one has been found in the German Bight ${ }^{1}$. Also the Odra River tests, conducted within the International Odra Project, showed the content of that type of compounds in water and bottoms ${ }^{2}$.

The main source of CIPE are installations that produce propylene oxide and epichlorohydrin. The amount of CIPE in the Odra River and the Elbe River is connected with the installations located near those rivers that produce propylene oxide. In the case of propylene oxide production, the most serious danger is caused by bis(1-chloro-2propyl) ether (BCIPE). It is formed as the main waste product in the phase of chlorohydroxylation. The scheme of its creation can be present by the reactions below

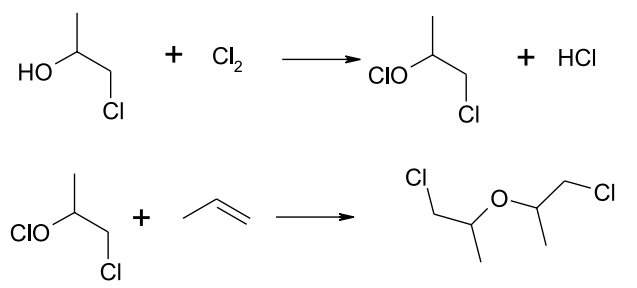

BCIPE has strong carcinogenic and mutagenic properties. Moreover, it is really hard biodegradable, which causes its cumulating in underground waters and bottoms.

The data shows that chlorinated propylene ethers pose serious danger to the environment. That is why such types of compounds have to be removed from wastewater in a more careful way. The optimum method, except for removing impurities, should also enable to recover the removed compounds. It allows reusing them or their safe utilization.

A nondestructive way of the process that only refers to mass transfer means that such requirements may be fulfilled by the adsorptive methods. Practically, using activated carbons allows a complete removal of hydrophobic chloroorganic compounds from water. However, they can be recovered in the desorption process ${ }^{4-6}$. Among the basic constructional solutions of adsorbers there is an apparatus with the fixed bed of adsorbent ${ }^{7}$. In addition, fixed-bed adsorption enables to easy carry out the adsorbent regeneration process. In this work the results of the studies of bis(1-chloro-2-propyl) ether adsorption from aqueous solution onto the fixed bed of adsorbent and the bed regeneration after its adsorption were presented.

\section{EXPERIMENTAL}

\section{Adsorption method}

The studies were carried out under the isothermal conditions $30 \pm 0.5^{\circ} \mathrm{C}$. The experimental installation was shown in Fig. 1. An aqueous solution of BCIPE was passed through a glass column with the diameter of $2.4 \mathrm{~cm}$ and height of $10 \mathrm{~cm}$, which was packed with activated carbon. The concentration of the feeding solution was $100 \mathrm{mg} /$ $\mathrm{dm}^{3}$. The solution was pumped by a peristaltic pump with the flow rate of 40 and $112 \mathrm{~cm}^{3} / \mathrm{min}$. The samples of the solution were collected at two heights of 5 and $10 \mathrm{~cm}$ and were analyzed for the content of BCIPE.

\section{Adsorbent regeneration}

Adsorbent regeneration studies were carried out with the method of sequential saturation and rinsing. $2 \mathrm{~g}$ of the adsorbent were inserted into the column (Fig.1), next the BCIPE aqueous solution was passed through it. The solution was pumped by the peristaltic pump with the flow rate of $10 \mathrm{~cm}^{3} / \mathrm{min}$ and the filtrate was received in a container. In each case the amount of the transmitted solution equaled $1 \mathrm{dm}^{3}$, whereas the BCIPE initial concentration was established on $190 \mathrm{mg} / \mathrm{dm}^{3}$. When the solution was passed through the bed, the amount of the 


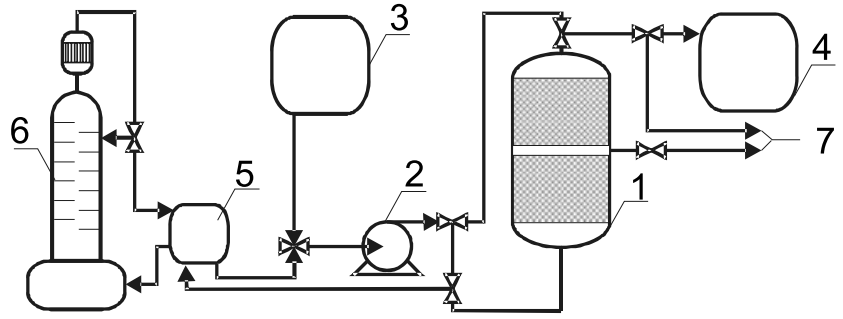

Figure 1. A diagram of the experimental installation, 1 - adsorber, 2 - peristaltic pump, 3, 4, 5 - reservoir of BCIPE solution, eluent and acetone adequate, 6 - distillation column, 7 - eluate sampling points

adsorbed BCIPE was evaluated on the basis of the mass balance:

$m_{a}=V\left(C_{0}-C_{k}\right)$

where: $C_{0}-$ BCIPE initial concentration $\left(\mathrm{mg} / \mathrm{dm}^{3}\right)$, $C_{k}$ - after adsorption BCIPE concentration $\left(\mathrm{mg} / \mathrm{dm}^{3}\right)$, $m_{a}$ - mass of the adsorbed BCIPE (mg), $V$ - solution volume $\left(\mathrm{dm}^{3}\right)$.

When the bed was saturated, the pump was switched over and the solvent was recycled to washout the adsorbed BCIPE. While the bed was being washing with the solvent, the measurement of BCIPE concentration was carried out.

\section{Analytical method}

The concentration of the BCIPE was determined chromatographically on a Thermoquest GC $8000^{\text {Top }}$ instrument with a flame ionization detector (FID). The determination was conducted with an internal standard method and the following analytical conditions: capillary column - RTX-5 (RESTEK) $30 \mathrm{~m} \times 0,53 \mathrm{~mm} \times 1,5 \mu \mathrm{m}$, carrier gas - He $5 \mathrm{~cm}^{3} / \mathrm{min}$, detector temperature $-250^{\circ} \mathrm{C}$, injector temperature $-250^{\circ} \mathrm{C}$ (split 1:10), oven - temperature program $-40^{\circ} \mathrm{C}(7 \mathrm{~min})$ to $180^{\circ} \mathrm{C}$ at $15^{\circ} \mathrm{C} / \mathrm{min}$. As an internal standard the o-xylene was used. To isolate the analyte from the matrix the dichloromethane extraction was used. $1 \mathrm{~cm}^{3}$ of the analyzed solution and $0.2 \mathrm{~cm}^{3}$ of oxylene solution $\left(100 \mathrm{mg} / \mathrm{dm}^{3}\right)$ in dichloromethane were placed in a polypropylene vial. The vial content was shaken for 10min. After phase separation, the dichloromethane phase was analyzed. The average error of this method equals $2.8 \%$.

\section{Adsorbent}

The adsorbent used in these studies was the activated carbon of the AG5 type supplied by GRYFSKAND SA (Poland). Sieved activated carbon was washed by distilled water to remove fines and then it was dried in an oven for $24 \mathrm{~h}$ at $110^{\circ} \mathrm{C}$. The properties of AG5 activated carbon are presented in Table 1.

Table 1. Parameters of the AG5 activated carbon

\begin{tabular}{|l|c|c|}
\hline Parameter & Unit & Value \\
\hline Bulk density & $\mathrm{g} / \mathrm{dm}^{3}$ & 428 \\
\hline Surface area & $\mathrm{m}^{2} / \mathrm{g}$ & 661 \\
\hline Pore volume & $\mathrm{cm}^{3} / \mathrm{g}$ & 0.447 \\
\hline Micropore volume $<1.5 \mathrm{~nm}$ & $\mathrm{~cm}^{3} / \mathrm{g}$ & 0.18 \\
\hline Equivalent diameter & $\mathrm{mm}$ & 1.27 \\
\hline Ash contents & $\%$ & $15-20$ \\
\hline $\mathrm{pH}$ of water extract & - & 9.3 \\
\hline
\end{tabular}

\section{RESULTS}

\section{Dynamic adsorption}

In Figs. 2 and 3 the breakthrough curves of BCIPE adsorption from aqueous solution on AG5 activated carbon were shown. On the basis of the course of dynamic adsorption of BCIPE from aqueous solutions on the AG5 activated carbon the essential parameters of adsorption bed were determined:

- adsorptivity of the bed from the balance:

$a_{s}=\frac{\rho}{m} \cdot\left(C_{o} \cdot V_{s}-\int_{0}^{V_{s}} C d V\right)$

where: $\rho$ - bulk density of the adsorbent $\left(\mathrm{g} / \mathrm{dm}^{3}\right), \mathrm{m}-$ mass of the adsorbent $(\mathrm{g}), V_{s}$ - volume of the solution flowing to the moment of bed saturation $\left(\mathrm{dm}^{3}\right)$

- adsorptivity of the bed to the breakthrough moment (dynamic adsorptivity):

$a_{d}=\frac{\rho}{m} \cdot\left(C_{o} V_{b}-\int_{0}^{V_{b}} C d V\right)$

where: $V_{b}$-volume of the solution flowing to the moment of bed breakthrough $\left(\mathrm{dm}^{3}\right)$

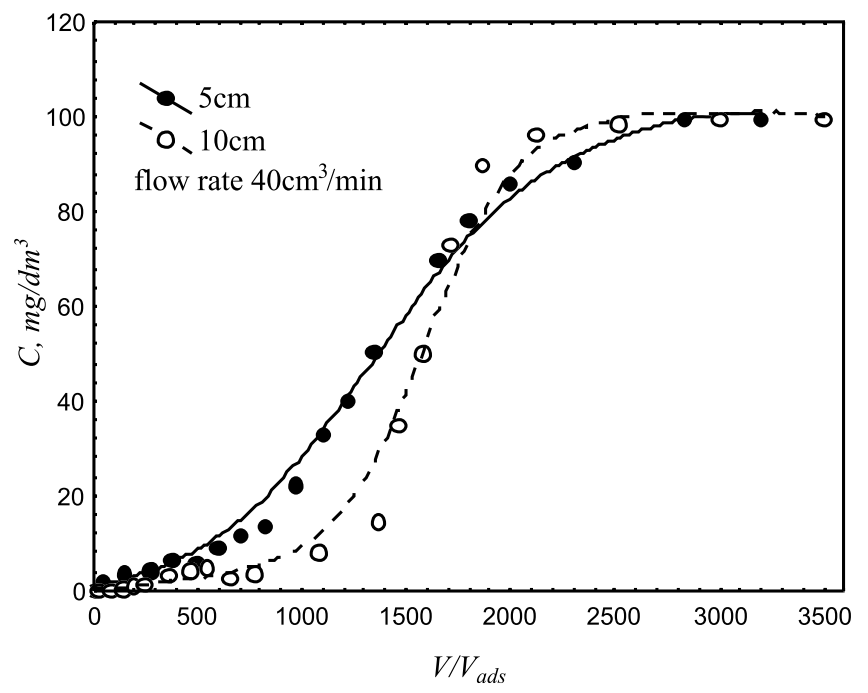

Figure 2. Breakthrough curves of BCIPE adsorption from the aqueous solution on the AG5 activated carbon flow rate $40 \mathrm{~cm}^{3} / \mathrm{min}$

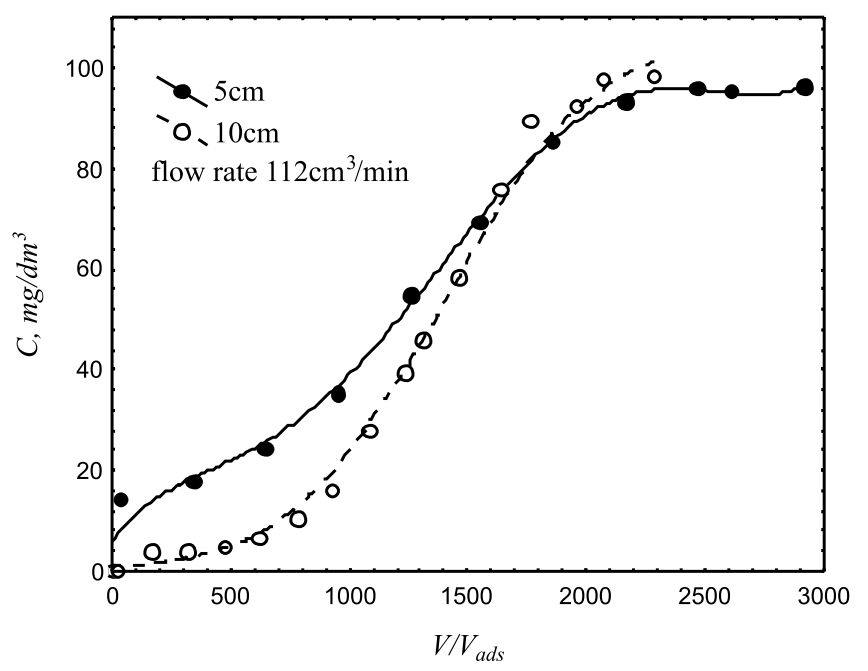

Figure 3. Breakthrough curves of BCIPE adsorption from the aqueous solution on the AG5 activated carbon flow rate $112 \mathrm{~cm}^{3} / \mathrm{min}$ 
Table 2. The determined parameters of the adsorption bed

\begin{tabular}{|l|c|c|c|c|c|}
\hline Parameter & Unit & \multicolumn{5}{|c|}{ Value } \\
\hline$q$ & $\mathrm{~cm} / \mathrm{min}$ & 40 & 40 & 112 & 112 \\
\hline$w$ & $\mathrm{~cm} / \mathrm{min}$ & 9 & 9 & 25 & 25 \\
\hline$H$ & $\mathrm{~cm}$ & 5 & 10 & 5 & 8 \\
\hline$a_{d}$ & $\mathrm{mg} / \mathrm{g}$ & 166 & 258 & 288 & 10 \\
\hline$a_{s}$ & $\mathrm{mg} / \mathrm{g}$ & 343 & 397 & 0.49 & 327 \\
\hline$\varphi$ & - & 0.57 & 0.58 & 21 & 0.54 \\
\hline$V_{\text {ads }}$ & $\mathrm{cm}$ & 22 & 44 & 7 & 33 \\
\hline$t_{b}$ & $\mathrm{~min}$ & 329 & 1109 & 563 & 300 \\
\hline$t_{s}$ & $\mathrm{~min}$ & 1497 & 372 & 285 & 773 \\
\hline$\Delta t$ & $\mathrm{~min}$ & 501 & 0.006 & 0.018 & 219 \\
\hline$U$ & $\mathrm{~cm} / \mathrm{min}$ & 0.005 & 5.5 & 10 & 0.018 \\
\hline$h$ & $\mathrm{~cm}$ & 5.9 & 0.65 & 0.03 & 8.5 \\
\hline$\eta$ & -- & 0.48 & & & 0.56 \\
\hline
\end{tabular}

- height of the mass transfer zone of the bed was calculated on the basis of Michaels equation ${ }^{8}$ :

$h=\frac{H \cdot\left(t_{s}-t_{b}\right)}{t_{s}-(1-\varphi) \cdot\left(t_{s}-t_{b}\right)}$

where: $H$ - bed depth $(\mathrm{cm}), t_{s}$ - time of bed saturation (min), $t_{b}$ - breakthrough time ( $\left.\min \right), \varphi$ - symmetry coefficient of the breakthrough curve $\varphi=S_{A} /\left(S_{A}+S_{B}\right), S_{A}$ - area above the adsorption curve to the moment of bed saturation, $S_{B}$ - area under the adsorption curve to the moment of bed saturation,

$$
\varphi=\frac{\left(t_{s}-t_{b}\right) \cdot C_{s}-\int_{t_{b}}^{t_{s}} C d t}{\left(t_{s}-t_{b}\right) \cdot\left(C_{s}-C_{b}\right)}
$$

$t_{b}=\frac{V_{b}}{q}$

$t_{s}=\frac{V_{s}}{q}$

where: $q$ - volume flow rate $\left(\mathrm{dm}^{3} / \mathrm{min}\right)$,

- rate of adsorption front migration was calculated from the formula?:

$U=\frac{H}{t_{s}-\Delta t}$

where: $\Delta t$ - time of adsorption front formation ${ }^{\mathbf{1 0}}$ :

$\Delta t=(1-\varphi) \cdot\left(t_{s}-t_{b}\right)$

- degree of adsorbent saturation at the breakthrough moment:

$\eta=\frac{a_{d}}{a_{s}}$

$a_{0}$ - adsorption capacity of the adsorbate for the concentration $C_{0}\left(\mathrm{~g} / \mathrm{dm}^{3}\right)$.

The determined parameters of bed adsorption were collected in Table 2. It was found that for the $5 \mathrm{~cm}$ bed depth, mass transfer zone (MTZ) is higher than the bed depth. This shows that for such bed depth, for the velocity of the flow both 9 and $25 \mathrm{~cm} / \mathrm{min}$, MTZ has not been completely formed. In the case of the $10 \mathrm{~cm}$ bed depth, for both velocities MTZ is shorter than the bed depth. It proves that MTZ has been formed completely there. Velocity acceleration from 9 to $25 \mathrm{~cm} / \mathrm{min}$ causes the increase of MTZ and decrease of adsorbent saturation degree $(\eta)$ in a relevant way. In the case of the $5 \mathrm{~cm}$ bed depth, $\eta$ decreasing is very important. However, for the higher bed depth $(10 \mathrm{~cm})$ that parameter is only $14 \%$ lower for the 2.8 times higher velocity of the flow. Using the higher bed depth enables much more bigger capacity of the installation with little deterioration of the parameters of the column work.

\section{Adsorbent regeneration}

Before the studies the most efficient washing out solvent was chosen. The selection was prepared for three readily available solvents - acetone, methanol and 2-propanol. So, $2 \mathrm{~g}$ of the saturated adsorbent was placed in a flask of $50 \mathrm{~cm}^{3}$ volume and drown with $50 \mathrm{~cm}^{3}$ of the solvent. Then the flask was shaken for $30 \mathrm{~min}$ and when the adsorbent fell, the solution for BCIPE content was analyzed. On the basis of the mass balance, the desorption degree from the equation below was determined:

$\eta_{d}=\frac{m_{a}}{m_{d}} \cdot 100 \%$

where: $m_{d}$ - mass of washing out BCIPE $(\mathrm{mg})$.

Table 3 shows the efficiency of BCIPE washing out from the activated carbon of the tested solvents. The obtained results present that acetone has the best washing out properties. Using that solvent led to a practically complete removal of BCIPE from the activated carbon.

Table 3. Washing efficiency of the study solvents

\begin{tabular}{|l|c|c|c|}
\hline \multirow{2}{*}{ Solvent } & $m_{a}$ & $m_{d}$ & $\eta_{d}$ \\
\cline { 2 - 4 } & $(\mathrm{mg})$ & $(\mathrm{mg})$ & $(\%)$ \\
\hline methanol & 177 & 43 & 4 \\
\hline acetone & 183 & 180 & 98 \\
\hline 2-propanol & 180 & 40 & 45 \\
\hline
\end{tabular}

In Table 4 the results of the following adsorption cycles with the use of acetone as a rinsing factor were set up. In the following tests the deterioration of the adsorption properties of the bed was not found. After each adsorption-desorption cycle also a practically complete removal of BCIPE from the bed has been obtained. After each cycle acetone was distilled off from the desorbate and when the loss was refilled, the recovered solvent was used in the next cycle.

\section{CONCLUSION}

The AG5 activated carbon possesses high efficiency of removing BCIPE from aqueous solutions. For the $10 \mathrm{~cm}$ 
Table 4. Degrees of bed desorption

\begin{tabular}{|c|c|c|c|}
\hline \multirow{2}{*}{ Process } & $m_{a}$ & $m_{d}$ & $\eta_{d}$ \\
\cline { 2 - 4 } & $(\mathrm{mg})$ & $(\mathrm{mg})$ & $(\%)$ \\
\hline 1 & 186 & 175 & 94 \\
\hline 2 & 195 & 190 & 97 \\
\hline 3 & 187 & 182 & 97 \\
\hline
\end{tabular}

bed depth dynamic adsorptivity of the AG5 activated carbon was $258 \mathrm{mg} / \mathrm{g}$ and $184 \mathrm{mg} / \mathrm{g}$, for the velocity of flow 9 and $25 \mathrm{~cm} / \mathrm{min}$ adequately. The adsorbent regeneration can be easily carried out by washing out adsorption bed with acetone. The regeneration adsorbent method used in this study enables to recover BCIPE from the desorbate in the distillation processes.

\section{LITERATURE CITED}

1. Franke, S., Hildebrandt S,. \& Francke, W. (1998). Chlorinated Bis(propyl)ethers and Clorinated Bis(ethyl)formals in the German Bight of the North Sea. Mar. Pollut. Bull. 36 (7), 546 - 551. DOI: 10.1016/S0025-326X(98)00031-9.

2. Kuczyńska, A., Wolska, L. \& Namieśnik, J. (2004) NonRegulated Organic Compounds (NROC's) in the Odra River Water Samples. P. J. Envir. Stud. 13 (3), 295 - 301.

3. Milchert, E. (1997) Technologies of the production of chloroorganic compounds. Waste utilization. ZAPOL, Szczecin. (in Polish).

4. Pełech, R., Milchert, E. \& Wróbel, R. (2006) Adsorption dynamics of chlorinated hydrocarbons from multi-component aqueous solution onto activated carbon. J. Hazard. Mater. 137 (3), 1479 - 1487. DOI: 10.1016/j.jhazmat.2006.04.023.

5. Pełech, R. (2008) Isotherms, Isosteres and Enthalpy of Adsorption of 1,2-dichloroethane From Aqueous Solution onto Activated Carbons. Ind. Eng. Chem. Res. 47 (15), 5615 - 5622. DOI: 10.1021/ie0715862.

6. Pełech, R., Milchert, E. \& Wróblewska, A. (2005) Desorption of chloroorganic compounds from fixed bed of activated carbon. J. Colloid Interf. Sci. 285 (2), 518 - 524. DOI: 10.1016/j.jcis.2004.12.012.

7. Pełech, R., Milchert, E. \& Bartkowiak, M. (2006) Fixedbed adsorption of chlorinated hydrocarbons from multi-component aqueous solution onto activated carbon. Equilibrium column model. J. Colloid Interf. Sci. 296 (2), 458 - 464. DOI: 10.1016/j.jcis.2005.09.020.

8. Michaels, A.S. (1952) Simplified Method of Interpreting Kinetic Data in Fixed-Bed Ion Exchange. Ind. Eng. Chem. 44 (8), 1922 - 1930. DOI: 10.1021/ie50512a050.

9. Paderewski, M.(1999) Adsorption processes in chemical engineering. WNT, Warszawa. (in Polish).

10. Romankow, P.G., Raszkowska, N.D. \& Frołow, W.F. (1980) Mass transfer processes in chemical technology. WNT, Warszawa. (in Polish). 